\title{
THE SEROLOGICAL TYPING OF HEMOLYTIC STREPTOCOCCI OF THE LANCEFIELD GROUP A
}

\author{
BY LOWELL A. RANTZ \\ (From the Department of Medicine, Stanford University School of Medicine, \\ San Francisco)
}

(Received for publication October 14, 1941)

The relationships among the hemolytic streptococci have been greatly clarified by the fundamental work of Lancefield (1). She has shown that these organisms may be classified into groups on the basis of a precipitin reaction and ample evidence has accumulated $(2,3)$ to show that almost all human infections are caused by members of her Group A.

Strains of the groups from $B$ to $K$ are responsible for many types of infection in animals, and occasionally in man, and are also frequent normal inhabitants of the human nose, throat and bowel. Non-hemolytic varieties are also well known among these groups (4).

The strains which are members of Group A may be further classified into more than 30 types by an agglutination test as described by Griffith (5). Many technical difficulties have prevented the widespread application of this procedure but the modifications of the original method suggested by Ward and Rudd (6) and further revised in this laboratory have made the serological typing of these streptococci simple and reliable.

The development of a satisfactory method of classifying the hemolytic streptococci pathogenic for man into types has offered a tool for the investigation of many aspects of the epidemiology, nature, and therapy of infections due to these organisms. Except for studies of epidemiology and observations on the relation of type to immunity, practically no answers have yet been obtained to the challenging questions which the availability of this method has raised.

A continuing study of hemolytic streptococcal infection in the San Francisco area has, therefore, been undertaken, and the Griffith classification has been applied for the purpose of gaining further information on the relationship of the serological types of Group A to disease states.

It is the purpose of this paper to review the published data bearing on this subject, to present certain modifications of method which increase the simplicity and reliability of the serological typing of the hemolytic streptococci and to state and discuss the results of the application of these methods to strains of streptococci isolated from infections and from normal human subjects in San Francisco during the seasons of 1940 and 1941.

\section{REVIEW OF THE LITERATURE}

Distribution of Griffith types in various disease states. Table I presents the collected data on nearly all of the extensive surveys of Griffith type distribution in various disease states available at the present time. For purposes of simplification and clarity no type occurring in less than 2 per cent of the examined strains in any series has been included and all percentage values are given to the nearest whole number.

From a study of these data certain important facts emerge. It may be definitely stated that no type or small group of types is regularly responsible for scarlet fever throughout the world. Types 1, 2, 3, and 4 occur frequently in Great Britain, the United States and Japan, but even in these areas a very large number of cases may be caused by other types. For example, in Edinburgh in 1933 to 1934, 66 per cent, and in London in 1937, 53 per cent of all strains did not fall into these four types. In Australia, types not included in those originally described by Griffith and identified locally ${ }^{1}$ are isolated from the majority of

1 Since the preparation of this paper, an opportunity to study strains of the local Australian types has been made available through the courtesy of Dr. F. G. Morgan of the Department of Health, Commonwealth of Australia.

Type "Hempston" appears to be identical with the Griffith type 3; type "Wade" with type 9; type "Stewart" with type 13 ; and type "Coghlan" with type 23.

"Wade" occurred more frequently than any other local type and is included in a separate column in table $I$. Fifty-six and a half per cent of the strains included in the same table under "local surgical types" were of types "Hempston," "Stewart" and "Coghlan." 


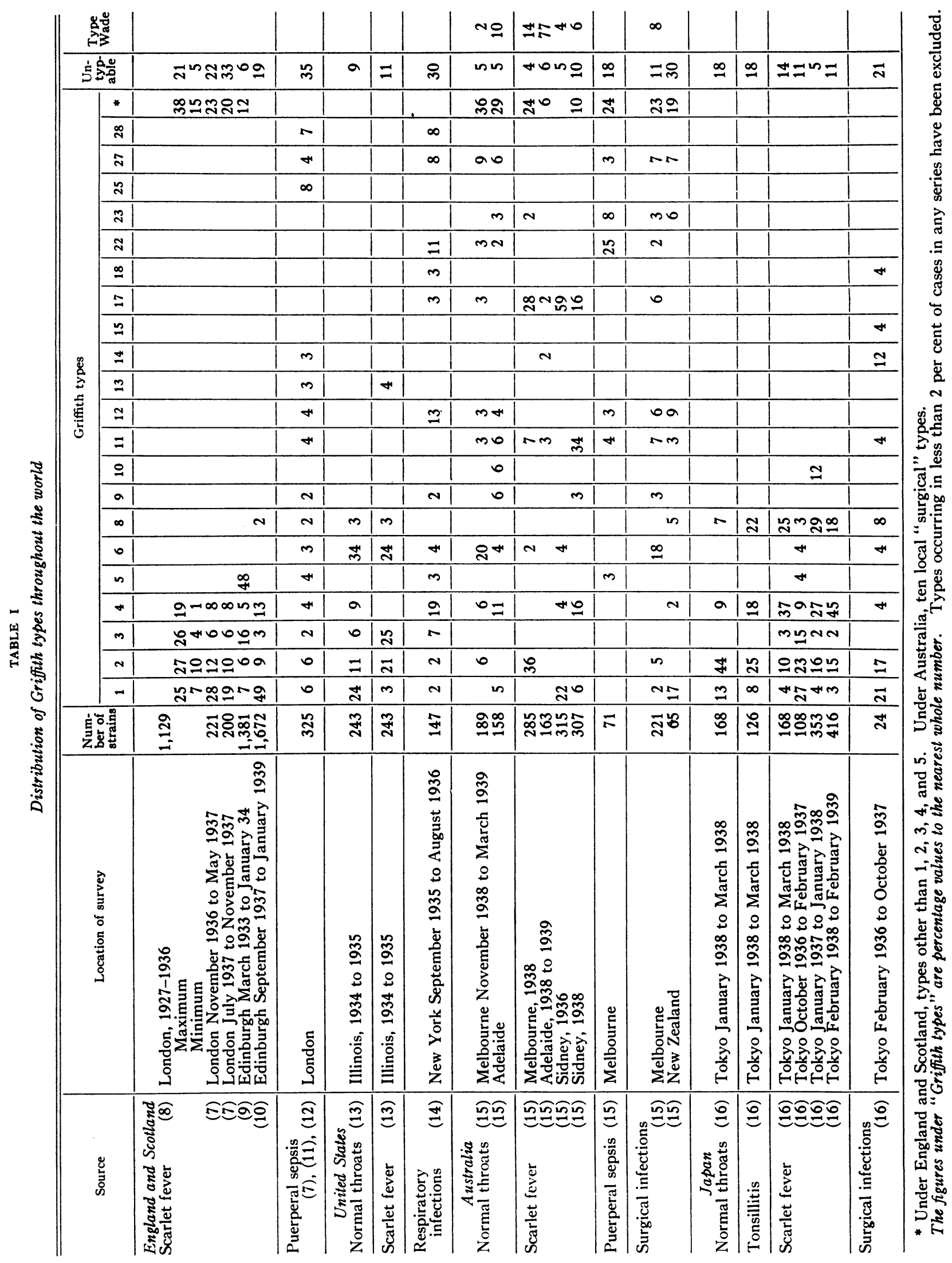




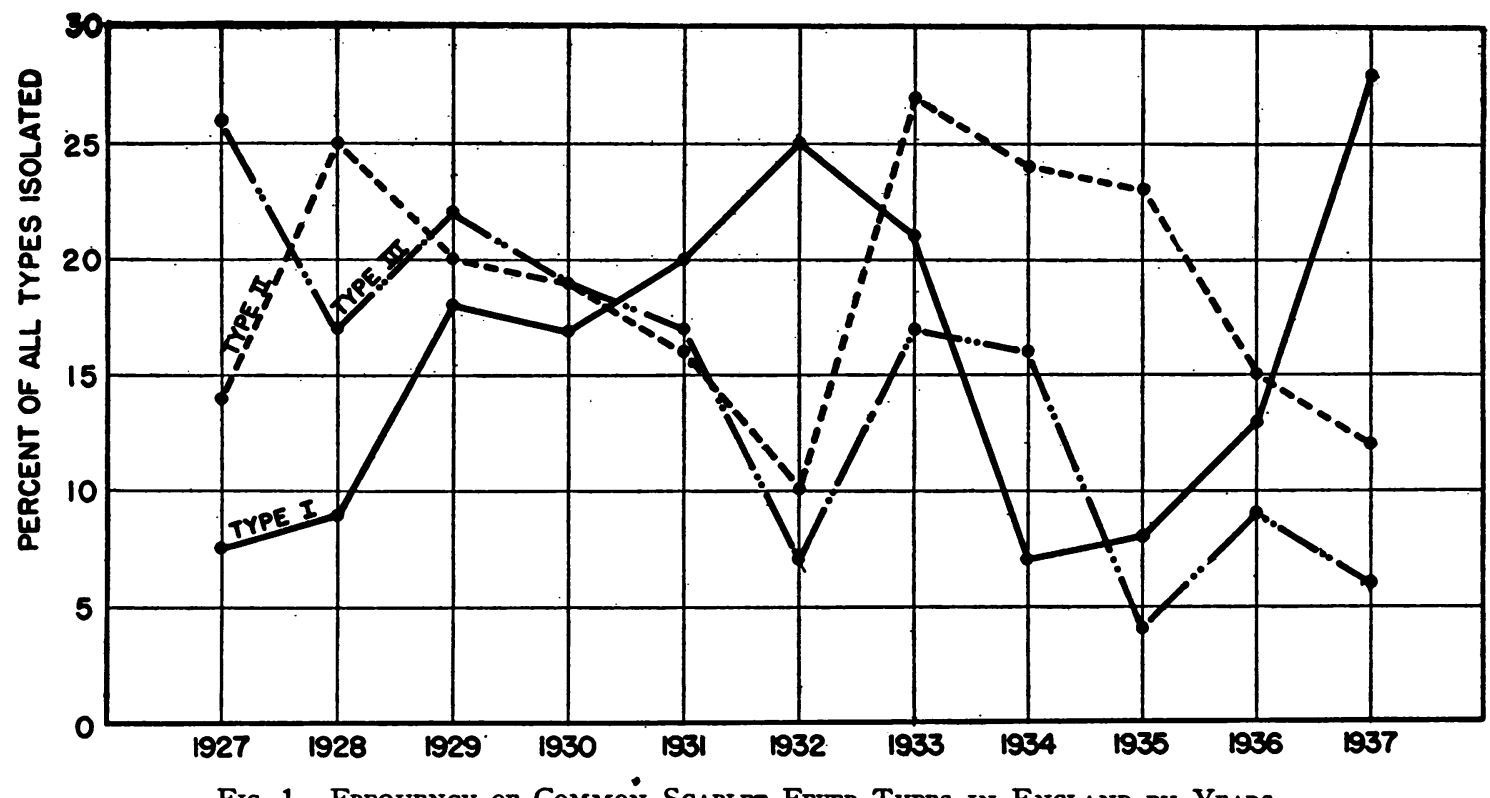

Fig. 1. Frequency of Common Scarlet Fever Types in England by Years

cases, the only common Griffith types being 1,2 , and 17. As might be expected, a few types are usually responsible for epidemics. It is striking, however, that the most frequent types are not the same from year to year in any area. In fact, in Tokyo, where observations were conducted over a 3-year period, Types 1 and 3, which were commonly present in cases of scarlet fever in 1936 to 1937, were very uncommon during 1937 to 1938 and 1938 to 1939, whereas Types 4 and 8, which were only occasionally isolated in the first season, accounted for 63 per cent of the cases in the last year.

This periodicity of occurrence of certain types (Figure 1) is derived from the data collected by Griffith (8) and Neisser (7) in London during the years 1927 to 1936 which show the percentage occurrence of the three most common types in cases of scarlet fever during this period. It will be observed that Type 1 presents two periods of more frequent occurrence-one 5 years in length, interspersed with two lows of 2 to 3 years' duration. The case in Types 2 and 3 is somewhat different. Here there was a gradual decline in frequency over 5-year periods followed by a sudden rise and another similar-period of decline.

Hemolytic streptococci of Group A are known $(15,17)$ to reside in the throats of normal individuals, and have been isolated and studied by the
Griffith method. The frequency of types isolated under these circumstances has not correlated well with the distribution of types isolated from tonsillitis and scarlet fever patients during the same season.

Only one investigation of the types of hemolytic streptococci found in tonsillitis without skin rash has been conducted in association with studies during the same period on cases of scarlet fever. In Tokyo, from January to March, 1938, 65 per cent of cases of tonsillitis and 62 per cent of cases of scarlet fever were shown to harbor strains of Type 2,4 , or 6 . While the intra-type frequency distribution is not identical in each case, it seems that epidemics of scarlet fever and tonsillitis occurring simultaneously may be caused by the same small group of types in each instance.

Too few data have been accumulated in hemolytic streptococcal infections of other than the nasopharynx to assess the relative importance of the various Griffith types in disease states. Two important observations have been made. First, it is unusual for any one type to be responsible for many cases of puerperal or surgical infection and the number of different types isolated from a significant number of cases is much greater than in scarlet fever. Second, while scarlet fever strains are perfectly capable of producing surgical infections and surgical strains scarlet fever, there is a 
general tendency for the two groups of diseases to be caused by different groups of organisms. For example, in London, only 22 per cent of cases of puerperal sepsis were caused by hemolytic streptococci of the 5 types most commonly found in scarlet fever, and in Australia the common scarlet fever types only occasionally were responsible for surgical infections and puerperal sepsis.

Epidemiology. Enormously valuable contributions to the knowledge of the epidemiology of hemolytic streptococcal infections have been made by the introduction of the Griffith classification. Some of these have been discussed in the previous section.

Colebrook (11) has shown that, in puerperal infections, the source of the infections may be traced in a large number of instances. In approximately 10 per cent it is found that the infecting organism has been harbored in the nasopharynx of the infected individual, but practically never in her genital passages. In the remaining cases, a physician, nurse, attendant, or member of the family is found to be the responsible carrier.

The comprehensive studies on war wound infections by Miles (18) have demonstrated that infections due to the hemolytic streptococcus spread from patient to patient and that waves of new infections follow the introduction into the ward of a fresh case infected with a new type. Epidemics of streptococcal respiratory infections within a closed group have been shown to be caused by a single type of streptococcus (19).

Severity of infection and complications. In spite of the large number of observations recorded in Table $I$, little information has been collected bearing on the relationship of the Griffith types to the severity of infection nor to the nature and type of complications. It has been shown by Brown and Allison (20) that suppurative complications such as otitis media following scarlet fever are usually the result of reinfection with a type different from that causing the initial infection and these observations have been amply confirmed by de Waal (10). As a general rule, complications occurring in the first week are caused by the initial type; those developing after this time are due to new types. In de Waal's series of 1,831 cases, 600 patients had complications of which only 20 per cent were associated with the type present on admission.
An analysis of his data, for the purpose of determining the relative tendency of various types to produce a more severe disease or complications, shows fairly clearly that there is a very real difference in the ability of the strains of the various types to cause complications and to prepare the soil for infection by other types.

Thus 48 per cent of initial Type 4 infections suffered complications, 30 per cent of Type 1,18 per cent of Type 2, and only 7 per cent of Type 3 . Type 1, which was the etiological agent in 49 per cent of the admitted cases, caused only 22 per cent of complications, whereas Type 4 , which was isolated from only 13 per cent of all cases on admission, was responsible for 20 per cent of all complications. The Type 4 cases are interesting for, not only were they more often complicated, but $6 \%$ per cent of the complications were caused by Type 4 rather than a new type.

Type 4 also appears to have caused otitis media about twice as frequently as Types 1 and 2 . Organisms of this type were therefore more virulent and highly invasive than those of the other common types in this particular epidemic.

Other observations bearing on these points have been made by Bailey (13), who found no difference in the complication rate among the cases included in Types 2, 3, and 6, his most frequently occurring types, and Pauli and Coburn (14) who have stated that, during a certain season in New York, Type 13 infections were more likely to reactivate rheumatic fever than were infections due to Type 22 .

It is impossible, therefore, to state definitely whether strains of certain types, when isolated from infections over wide geographical areas, will be uniformly more virulent than others, or whether this phenomenon will be a purely local one, varying from season to season, or epidemic to epidemic, but it is clear that there have been differences in the invasiveness of certain types in carefully studied epidemics.

Animal virulence and toxin formation. An extensive study of the relation of the serological type of Group A streptococci isolated from cases of scarlet fever to animal virulence has been made by Kodama and his associates (16c). A constant and very large infecting dose of organisms was used with white mice as test arimals. Sixty-one 
strains of Type 2, 189 of Type 4, and 77 of Type 8 were studied. The mortality rates in the infected animals were $16.4,25.4$, and 20.8 per cent, respectively. Too small a number of strains of other types were studied for satisfactory conclusions to be drawn. The differences in mortality are small and not statistically significant, but suggest that Type 4 was more virulent than Type 2 . They further studied 10 strains each of 5 types after serial mouse passage, but failed to demonstrate any difference in the degree of mouse pathogenicity after this procedure.

Erythrogenic toxin production for the strains of streptococci described above was also studied by Kodama and his associates. Seventy-two and two-tenths per cent of Type 2, 91.6 per cent of Type 4, and 86.9 per cent of Type 8 strains formed this toxin. These differences are not as definite as those given above for mouse virulence. The ability of organisms of the various types to form this toxin has also been studied by Bailey (13). Only small numbers of strains were studied but this product was formed by streptococci of Type 3 much more frequently than by those of Types 4 and 6 . These observations are probably statistically significant.

Relation of serological type to therapy. It has been amply shown by Loewenthal (21) and Lyons (22) that sera for the protection of experimental animals against hemolytic streptococcal infections must contain homologous type specific antibodies. This fact undoubtedly accounts for the failures of many early attempts at the preparation of therapeutic sera. Since the development of adequate methods of serological typing, type specific therapeutic sera have been prepared in animals but have received little clinical trial. Platou, Dwan and Hoyt (23) have described in vitro experiments which demonstrate a feeble antibacterial activity in type specific convalescent scarlet fever sera, and are investigating the use of such sera in the treatment of this disease.

No data are available, either of an experimental or clinical nature, which may be used to determine the response of infections due to the various types of hemolytic streptococci to the several sulfonamides.

\section{METHODS}

1. Isolation of organisms and Lancefield classification. All the strains of hemolytic streptococci described in this study have been isolated from individuals suffering from various types of hemolytic streptococcal infections or from the excised tonsils of normal persons. The procedures used in the isolation and Lancefield classification of these organisms have been described elsewhere (17). All strains were demonstrated to be members of Group A.

2. Griffith typing. Since the development by Griffith of an agglutination method for the division of strains of hemolytic streptococci of the Lancefield Group A into types, various modifications of his methods have been proposed. These have been directed at the preparation of better agglutinating suspensions and of sera more nearly free from intra-type cross reactions. Procedures used in this study will be described in detail:

a. Agglutinating suspensions. Two principal difficulties have been encountered in the preparation of satisfactory agglutinating suspensions: the first and most serious is the failure of the streptococci to grow diffusely in broth culture; the second is the tendency of certain strains to be inagglutinable even though the suspension is otherwise satisfactory. Repeated rapid transfer in liquid media or the addition of certain substances, such as serum, ascitic fluid (5), or live trypsin (24) to nutrient broth has been proposed for the elimination of granular suspensions. Considerable experience with each of these showed that none was entirely satisfactory. Serial passage in broth was exceedingly time-consuming; the addition of serum and of trypsin produced a very high percentage of inagglutinable suspensions.

Exceedingly satisfactory suspensions for the agglutination test were obtained if the cultures were incubated at a temperature below $30^{\circ} \mathrm{C}$., as suggested by Ward and Rudd (6) but, under these conditions, growth of sufficient density developed very slowly. Usable suspensions have been secured within a reasonable period of incubation in the following manner: small tubes containing 2 to 3 cubic centimeters of tryptic digest broth (14) were inoculated with a large loopful of the organism to be studied, which had been freshly transferred on blood agar plates. The tube was closed with a sterile rubber stopper, and incubated in a rotating box at room temperature for 15 to 18 hours. Approximately 90 per cent of all strains yielded suspensions satisfactory for the slide agglutination test by this method.

A small number formed granular suspensions when cultivated in this way. These can be improved by adding a drop of trypsin solution (Difco) to the sediment and incubating for from 15 to 60 minutes at $37^{\circ} \mathrm{C}$. The preparation must be examined frequently and typing carried out as soon as the granularity has disappeared, as prolonged incubation increases the incidence of inagglutinable suspensions.

Considerable numbers of strains which were untypable when first studied were readily typed after cultivation 
and storage for several weeks or even months in nutrient agar stabs with agar seal at $5^{\circ} \mathrm{C}$. Some of these strains were inagglutinable on the first examination but most of them tended to show agglutination in sera of several different types. This was especially true of a large number of strains of Type 12 which also agglutinated in Type 13 serum and strains of Type 11 which agglutinated in Type 12 serum. Nearly all of these were entirely type specific when retyped after storage in the manner described above. This phenomenon is probably related to the development in storage of glossy variants which Lancefield (25) has proposed as most suitable for typing by the agglutination technique because of their simpler antigenic structure.

b. Type sera. The typing sera used in this study were provided in crude undiluted form by the Lederle Laboratories and were prepared in rabbits. The titer of each was determined by a simple method. Undiluted serum was added, drop by drop, to 2 cubic centimeters of normal saline until agglutination of the homologous type was just observed, and then approximately 25 per cent more serum was added. Each dilute serum was then tested against suspensions of known Griffith type strains of hemolytic streptococci. Those showing cross reactions required absorption. This was best accomplished by the use of a non-type-specific variant of one of the ordinary type strains. Griffith (7) has described a method for the preparation of such a variant by the growth of Type 3 organisms upon agar containing homologous serum. Certain strains of Group A, however, which had been maintained on artificial culture media for a long period of time, showed colonies of more than one form when plated out. Suspensions prepared from a number of these usually yielded at least one which failed to agglutinate in the homologous serum. Such a strain was then cultured in large volumes of nutrient broth. After 18 hours of incubation the organisms were removed by centrifugation; those derived from 100 cubic centimeters were used for the absorption of 1 cubic centimeter of diluted serum. This operation was performed at $37^{\circ} \mathrm{C}$. in a rotator. The serum was tested against agglutinating suspensions at hourly intervals and, when the cross reaction had been eliminated, the absorbing organisms were immediately removed in the centrifuge, the serum transferred to a sterile tube, and merthiolate added to a concentration of 1 to 10,000 . Following such absorption a few sera still showed cross reactions for certain types. These were eliminated by absorption in the manner described above, using organisms of the type with which crossing occurred.

Much time was saved by preparing pools of sera of various types. - It was advisable to combine in groups the sera for types among which cross agglutination occurred. Four sera selected in this way were mixed, diluted 1 to 2 and lightly absorbed with the organisms from 100 to 200 cubic centimeters of broth culture. Such pools, while not absolutely specific, usually limited the number of type sera required to 8 or less.

c. The slide agglutination test. Two cubic centimeters of a broth culture prepared as described above were centrifuged and nearly all of the supernatant broth poured off. Drops of this thick suspension were placed with a platinum loop, 1.0 millimeter in diameter, upon a glass slide ruled into small squares by means of a wax pencil. The pooled sera were mixed with the drops of suspension by means of a 32 gage Nichrome wire loop, $1 / 2$ to $3 / 4$ millimeter in diameter. The slide was rotated and then examined with a hand lens against a rather dark background and agglutination was observed in one or more pools. The specific sera contained in these pools were then set up in exactly the same manner with the suspensions.

This method has been most satisfactory and definite type specific agglutination was obtained with practically all of the typed strains. Repeated attempts were made to differentiate the several available strains of Types 4 and 24 by agglutinin absorption of the Lederle sera and sera obtained from Dr. Griffith. It was in no case possible to distinguish between these two types and, for the purpose of this study, strains agglutinating in Types 4 and 24 sera have been included in Type 4 .

The procedures described have permitted the accurate classification of from 80 to 95 per cent of all strains. The number of typable strains appeared to vary with the source of the material.

\section{SOURCE OF MATERIAL}

A brief description of the type of clinical material from which the strains of hemolytic streptococci described in this study were isolated is pertinent.

Otitis Media. This group of 64 strains was isolated from materials obtained from the ears of children whose presenting complaint in the clinic, in nearly every instance, was referable to an infection of the middle ear or mastoid process. Many had a previous history of respiratory infection or sore throat, but none of scarlet fever.

Nasopharynx. The 28 strains included in this group were isolated from individuals who were suffering, or had shortly before suffered, a typical attack of tonsillitis.

Excised Tonsils. All tonsils excised in the clinic service of Stanford Hospitals since February, 1940, have been studied for the presence of hemolytic streptococci and the results described in detail elsewhere (17). All the Group A strains, which were isolated and typed by the methods described in this paper, have been included-112 in all. Strains isolated during the months of February to October, 1940, have been included under 1940, and those from October, 1940 to July, 1941, under 1941.

Scarlet Fever. All of the cases of scarlet fever admitted to the San Francisco Hospital from February, 1941 to July, 1941, were studied. Group A hemolytic streptococci were recovered in 15 of 17 cases.

Miscellaneous. This group of 41 strains includes 27 isolated from various surgical infections, usually cellulitis of an extremity. Also included are 3 obtained from the spinal fluid of meningitis cases, 7 from cases of pneumonia or acute bronchitis, 1 from puerperal sepsis and 3 cultured from the urine. 


\section{RESULTS}

The results obtained in the serological typing by the Griffith method of strains of hemolytic streptococci isolated from various sources in 148 instances of hemolytic streptococcal infection and from the excised tonsils of 112 normal individuals are presented in Table II.

No strains of Types $3,8,14,18,19,22,26,28$, 29 , or 30 were isolated. Types $7,16,20$, and 21 are not members of Group A (14). The data presented under five headings based on the source of material, and the percentage values are calculated for each division separately. Totals are presented for 1940 and 1941 separately and combined with percentages calculated for each year and, in the last instance, for all strains.

Seasonal variations in types. Striking seasonal variations in the isolated types were noted. Types 1 and 2, which included 20.6 per cent of the isolated strains in 1940, were found in only 6.2 per cent of cases in 1941. Types 6 and 11 were more common in 1941, but two common types, 12 and 25 , showed little variation in total number during the two seasons.

If the data for the 2 years are studied separately in relation to the source, which has been done but not included in the table, it is found that Types 1 and 2, which were isolated from 31 per cent of cases of clinical infection in 1940 , were present in only about 2 per cent in 1941 . Practically all of the examples of these two types in 1941 were recovered from excised tonsils, where they had probably been resident since the previous season. Types 12 and 25 each occurred about twice, and Type 6 about 10 times as frequently in infectious states in 1941 as in 1940.

These variations are not nearly so striking if the strains from excised tonsils are considered for the 2 years. Types 1 and 2 appear only about one-third as frequently in 1941, but most of the other types were present in numbers of about the same order of magnitude in each year. Type 12 was present much less often in the tonsils in 1941, though more often a cause of infection than in the previous year.

Relationship of serological type to source of material. An examination of the composite data for the 2 years included in this study shows that the type distribution in strains from various sources is quite similar with a few notable exceptions. If the strains from otitis media, mastoiditis and tonsillitis be included together as examples of infection of the nasopharynx and its complications, and if the type distribution of the

TABLE II

Distribution of Griffith types among strains of Group $A$ hemolytic streptococci isolated in the San Francisco area

\begin{tabular}{|c|c|c|c|c|c|c|c|c|c|c|c|c|c|c|c|c|c|c|}
\hline \multirow{2}{*}{ Source } & \multirow{2}{*}{$\begin{array}{l}\text { Num- } \\
\text { ber of } \\
\text { strains }\end{array}$} & & \multicolumn{15}{|c|}{ Griffith types } & \multirow{2}{*}{$\begin{array}{c}\text { No } \\
\text { type }\end{array}$} \\
\hline & & & 1 & 2 & 4 & 5 & 6 & 9 & 10 & 11 & 12 & 13 & 15 & 17 & 23 & 25 & 27 & \\
\hline Otitis media. . & 64 & $\begin{array}{l}\text { Number } \\
\text { Per cent }\end{array}$ & $\begin{array}{l}5 \\
7.8\end{array}$ & $\begin{array}{c}8 \\
12.5\end{array}$ & $\begin{array}{l}3 \\
4.7\end{array}$ & $\begin{array}{l}1 \\
1.6\end{array}$ & $\begin{array}{l}5 \\
7.8\end{array}$ & & $\begin{array}{l}1 \\
1.6\end{array}$ & $\begin{array}{l}2 \\
3.1\end{array}$ & $\begin{array}{c}9 \\
14.1\end{array}$ & & $\begin{array}{l}2 \\
3.1\end{array}$ & & $\begin{array}{l}1 \\
1.6\end{array}$ & $\begin{array}{l}22 \\
34.3\end{array} \mid$ & $\begin{array}{l}2 \\
3.1\end{array}$ & $\begin{array}{l}3 \\
4.7\end{array}$ \\
\hline Nasopharynx. . & 29 & $\begin{array}{l}\text { Number } \\
\text { Per cent }\end{array}$ & $\begin{array}{c}3 \\
10.4\end{array}$ & $\begin{array}{c}3 \\
10.4\end{array}$ & $\begin{array}{c}3 \\
10.4\end{array}$ & & $\begin{array}{l}1 \\
3.4\end{array}$ & & $\begin{array}{l}1 \\
3.4 \\
\end{array}$ & & $\begin{array}{c}3 \\
10.4 \\
\end{array}$ & & & & $\begin{array}{c}4 \\
13.8 \\
\end{array}$ & $\begin{array}{c}4 \\
13.8 \\
\end{array}$ & $\begin{array}{l}1 \\
3.4\end{array}$ & $\stackrel{6}{60.6}$ \\
\hline Miscellaneous. . & 41 & $\begin{array}{l}\text { Number } \\
\text { Per cent }\end{array}$ & $\begin{array}{l}3 \\
7.6\end{array}$ & $\begin{array}{l}3 \\
7.6\end{array}$ & $\begin{array}{l}1 \\
2.4\end{array}$ & $\begin{array}{l}3 \\
7.6\end{array}$ & $\begin{array}{l}2 \\
4.9\end{array}$ & $\begin{array}{l}1 \\
2.4\end{array}$ & & & $\begin{array}{c}7 \\
17.1\end{array}$ & $\begin{array}{l}1 \\
2.4\end{array}$ & $\begin{array}{l}1 \\
2.4\end{array}$ & $\begin{array}{l}1 \\
2.4\end{array}$ & $\begin{array}{l}2 \\
4.9\end{array}$ & $\begin{array}{c}5 \\
12.2\end{array}$ & $\begin{array}{l}3 \\
7.6\end{array}$ & $\begin{array}{c}8 \\
19.5\end{array}$ \\
\hline Excised tonsils. & 112 & $\begin{array}{l}\text { Number } \\
\text { Per cent }\end{array}$ & $\begin{array}{l}7 \\
6.2\end{array}$ & $\begin{array}{l}19 \\
17.0\end{array}$ & $\begin{array}{l}10 \\
8.8\end{array}$ & $\begin{array}{l}1 \\
0.9\end{array}$ & $\begin{array}{l}3 \\
2.6\end{array}$ & & $\begin{array}{l}1 \\
0.9\end{array}$ & $\begin{array}{l}3 \\
2.6\end{array}$ & $\begin{array}{l}15 \\
13.4\end{array}$ & $\begin{array}{l}7 \\
6.3\end{array}$ & $\begin{array}{l}4 \\
3.6\end{array}$ & & $\begin{array}{l}2 \\
1.7\end{array}$ & $\begin{array}{l}15 \\
13.4\end{array}$ & $\begin{array}{l}3 \\
2.6\end{array}$ & $\begin{array}{l}22 \\
19.6\end{array}$ \\
\hline Scarlet fever-1941 .... & 15 & $\begin{array}{l}\text { Number } \\
\text { Per cent }\end{array}$ & & $\begin{array}{l}1 \\
6.7\end{array}$ & $\begin{array}{l}1 \\
6.7\end{array}$ & & & & & $\begin{array}{c}6 \\
40.0\end{array}$ & & & & & $\begin{array}{l}1 \\
6.7\end{array}$ & $\begin{array}{c}4 \\
26.5\end{array}$ & & $\begin{array}{c}2 \\
13.4\end{array}$ \\
\hline $\begin{array}{l}\text { Total-1940 } \\
\text { (January to December) }\end{array}$ & 147 & $\begin{array}{l}\text { Number } \\
\text { Per cent }\end{array}$ & 17 & $\begin{array}{l}28 \\
19.0\end{array}$ & $\begin{array}{l}9 \\
6.1\end{array}$ & $\begin{array}{l}2 \\
1.4\end{array}$ & $\begin{array}{l}2 \\
1.4\end{array}$ & & $\begin{array}{l}2 \\
1.4\end{array}$ & $\begin{array}{l}1 \\
0.7\end{array}$ & $\begin{array}{l}20 \\
13.6\end{array}$ & \begin{tabular}{l|}
2 \\
1.4
\end{tabular} & $\begin{array}{l}3 \\
2.0\end{array}$ & $\begin{array}{l}1 \\
0.7\end{array}$ & $\begin{array}{l}4 \\
2.7\end{array}$ & $\begin{array}{l}30 \\
20.3\end{array}$ & $\begin{array}{l}6 \\
4.1\end{array}$ & $\begin{array}{l}20 \\
13.6\end{array}$ \\
\hline $\begin{array}{l}\text { Total-1941 } \\
\text { (January to July)...... }\end{array}$ & 113 & $\begin{array}{l}\text { Number } \\
\text { Per cent }\end{array}$ & $\begin{array}{l}1 \\
.0 .9 \\
\end{array}$ & $\begin{array}{l}6 \\
5.3\end{array}$ & $\begin{array}{l}8 \\
7.1 \\
\end{array}$ & $\begin{array}{l}3 \\
2.6 \\
\end{array}$ & $\begin{array}{l}9 \\
7.9 \\
\end{array}$ & $\begin{array}{l}1 \\
0.9\end{array}$ & & $\begin{array}{c}10 \\
8.7\end{array}$ & $\begin{array}{l}9 \\
7.9\end{array}$ & $\begin{array}{l}7 \\
6.2 \\
\end{array}$ & $\begin{array}{l}4 \\
3.5 \\
\end{array}$ & & $\begin{array}{l}6 \\
5.3\end{array}$ & \begin{tabular}{l|}
21 \\
18.6
\end{tabular} & $\begin{array}{l}3 \\
2.6\end{array}$ & $\begin{array}{l}25 \\
22.1\end{array}$ \\
\hline Total-1940 and 1941. & 260 & $\begin{array}{l}\text { Number } \\
\text { Per cent }\end{array}$ & $\begin{array}{c}18 \\
6.9\end{array}$ & \begin{tabular}{l|}
34 \\
13.1
\end{tabular} & $\begin{array}{c}17 \\
6.5\end{array}$ & \begin{tabular}{l|}
5 \\
1.9
\end{tabular} & $\begin{array}{c}11 \\
4.2\end{array}$ & $\begin{array}{l}1 \\
0.4\end{array}$ & $\begin{array}{l}2 \\
0.8\end{array}$ & $\begin{array}{c}11 \\
4.2\end{array}$ & $\begin{array}{l}29 \\
11.2\end{array}$ & \begin{tabular}{l|}
9 \\
3.5
\end{tabular} & $\begin{array}{l}7 \\
2.7\end{array}$ & \begin{tabular}{|l|}
1 \\
0.4
\end{tabular} & $\begin{array}{c}10 \\
3.8\end{array}$ & \begin{tabular}{|l|}
51 \\
19.5
\end{tabular} & $\begin{array}{l}9 \\
3.5\end{array}$ & $\begin{array}{l}45 \\
17.3\end{array}$ \\
\hline
\end{tabular}


7 most frequent types be compared with that for the same types isolated from a group of infections, most of which are "surgical" in nature (Table III), it will be noted that, except for Type 25, the percentage incidence of the types in each group is very similar. The distribution of strains from excised tonsils is included in this table and shows a similar pattern in most instances.

TABLE III

Percentage of seven most common types in San Francisco by source

\begin{tabular}{|c|c|c|c|c|c|c|c|c|c|}
\hline \multirow{2}{*}{ Source } & \multirow{2}{*}{$\begin{array}{l}\text { Num- } \\
\text { ber of } \\
\text { strains }\end{array}$} & \multicolumn{7}{|c|}{ Griffith types } & \multirow{2}{*}{ Total } \\
\hline & & 1 & 2 & 4 & 6 & 12 & 23 & 25 & \\
\hline $\begin{array}{c}\text { Otitis media and ton- } \\
\text { sillitis............. }\end{array}$ & 74 & 7.8 & 10.6 & 5.8 & 5.8 & 11.6 & 4.9 & 25.0 & 71.5 \\
\hline Surgical infections.... & 41 & 7.6 & 7.6 & 2.4 & 4.9 & 17.1 & 4.9 & 12.2 & 56.7 \\
\hline Excised tonsils. & 112 & 6.2 & 17.0 & 8.8 & 2.6 & 13.4 & 1.7 & 13.4 & 63.1 \\
\hline
\end{tabular}

The frequency with which Type 25 has been isolated from cases of otitis media during this survey is most striking. It is also important to note that it predominates in this manner only among the strains isolated from this disease.

Too small a number of examples of the various types of hemolytic streptococcal disease have been studied to draw conclusions in regard to the relationship of type to any of the other manifestations of infection due to this organism. It is worthwhile, however, to note that, in 3 cases associated with bacteremia, Types 1, 5, and 6 were involved, and that Type 5 was responsible for the 2 cases of meningitis studied. This type, while exceedingly uncommon, was therefore isolated from 3 of the 5 most seriously ill patients.

Relationship of source to typability. All of the strains of hemolytic streptococci described have been studied by identical methods and approximately the same incidence of untypable strains was found in the various groups, except those derived from ear and mastoid infections in which only 5 per cent were not classified as contrasted with about 20 per cent of all other strains. This very marked difference cannot be explained. It may be that more highly invasive strains lend themselves to typing more readily because of antigenic changes in the organism, or that these strains simply happen to be members of the described Griffith types more frequently than strains from other sources in the San Francisco area.

\section{DISCUSSION}

Technical difficulties, which may be largely avoided by procedures similar to those described in this paper, have prevented the widespread application of the Griffith method for the serological classification into types of hemolytic streptococci of the Lancefield Group A. This is unfortunate since these types have the same application in the study of hemolytic streptococcal infections that pneumococcal typing offered in the investigation of infections due to these organisms.

From the data presented in this paper and from those of other workers, certain definite facts emerge. Recovery from Group A hemolytic streptococcal infections is associated with the development in the host of type specific antibodies. No small group of types is responsible for scarlet fever throughout the world, but there is adequate evidence that in any community the same types are regularly responsible for this disease, the incidence of individual types varying from year to year. It is not possible to determine at present why these variations should occur. It may be due either to shifting immunity in the potential host population, or to changes in the invasiveness of the organism in association with the production of infection. Coburn and Pauli (26) have studied certain aspects of the latter hypothesis and feel that recovery from infection of the nasopharynx in adults, but not in children, is associated with loss of infectiveness on the part of the hemolytic streptococcus. This work is entirely unconfirmed.

The same types responsible for scarlet fever may cause tonsillitis without rash. This important observation has finally settled the question as to the presence of a specific "scarlet fever streptococcus." It is obvious that the most important factor governing the production of the two diseases is the state of antitoxic immunity in the individual at the onset of the infection. That important differences in the nature of the organism must also exist is suggested by the numerous instances in which hemolytic streptococcal pharyngitis without rash has occurred one or more times in individuals who have later acquired scarlet fever.

Hemolytic streptococci of the types commonly responsible for scarlet fever may also cause surgical infections, but in most of the previous studies 
they have not predominated as etiological agents in the latter conditions. It is of interest to point out that, among the strains described in this paper, the incidence of types in surgical and respiratory infections was similar. This was also true among strains collected in the Boston area (27).

In the United States, therefore, hemolytic streptococcal infections, regardless of the site of the disease process, are caused by similar small groups of types. Instances of sporadic infection due to types of streptococci not at that time commonly causing infection appear to be no more common among the group of "surgical" than among the respiratory infections.

The strains of streptococci isolated from the excised tonsils of healthy persons do not, season by season, mirror exactly the distribution of types responsible for infections during the same interval. This is to be expected since streptococci that have gained residence within the tonsils tend to remain there for long periods of time (17), so that strains collected from this source will be partly the residue of previous seasons and partly the result of invasion by types currently common in disease states. It seems almost certain that the tonsils of such carriers must be the reservoir from which infection spreads out into the community each season.

Many of the suppurative complications associated with and following hemolytic streptococcal pharyngitis and scarlet fever have been shown to be caused by reinfection with a type of streptococcus different from.that present at the onset of the disease. This is particularly true of complications arising after the first week of the illness.

Some evidence exists that strains of different types vary in their virulence for mice and their toxigenicity. That certain types are more invasive in man is suggested by the fact that a few cause most of the clinical infections in the community, though many others may be demonstrated to be present in the throats of healthy carriers. It is also clear that some types are more apt to produce severe disease or to prepare the soil for complications involving cross infection by a streptococcus of another type. This is well demonstrated by the work of de Waal, and is suggested by the frequency with which Type 25 has heen isolated from otitis media in this survey. Of strains isolated from examples of this infection, this type was observed more than twice as frequently as were the strains of any other type. It is also important to note that Type 25 predominates in this manner only in this disease, suggesting that it was more likely to produce complications after invading the nasopharynx than the other types. It is possible that Type 25 was more commonly present in the community than the data obtained in this study indicate. This impression is supported in part by the fact that several of the small series of scarlet fever strains were members of Type 25 . If this were so, then the other common scarlet fever type might have been expected to have appeared as a frequent cause of otitis media, which is not the case. This evidence, then, strongly suggests that strains of Type 25 were more actively invasive than those of other types and have continued to be so over a 2 -year period.

Whether this enhanced pathogenicity is a permanent property of strains of certain types cannot yet be determined but it is extremely unlikely that any will prove to be consistently more virulent over wide geographic areas.

Such variations in the type and severity of disease, if confirmed and extended, might be of great value in determining prognosis and therapy of streptococcal infections. No definite evidence is available as yet bearing on the relationship of the serological type of hemolytic streptococcus to treatment with sulfonamides, but preliminary observations (28) suggest that there may not be any real differences in this respect among infections caused by the various types.

It has been possible to prepare satisfactory antitoxic antisera for the treatment of scarlet fever and other infections caused by the hemolytic streptococcus, since these substances are not related to serological type. Any sort of useful antibacterial antibody must, however, be type specific. For this reason it has been proposed (23) that convalescent scarlet fever sera be collected in type specific pools, the etiological organisms being typed before serum is administered. Such a method would be feasible because only a small number of types are isolated from cases of this disease during any season. Such sera would be of low antibody titer and their clinical value could be 
determined only by trial. Suitable sera could probably be prepared in animals.

The importance of the application of serological typing to the study of the epidemiology of hemolytic streptococcal infections is obvious. The work of Colebrook (11) has shown the importance of carriers in the introduction of infection in the puerperal state, and Miles (18) has demonstrated that wound infections spread from patient to patient in the hospital ward and has indicated the rôle of attendants in this process. The importance of reinfection with new types in the development of complications in scarlet fever wards has been commented upon, and indicates the necessity for the isolation of such cases in wards according to the type of infecting streptococcus.

The study of epidemics of streptococcal infections by serological typing of the infecting organisms may lead to their more rapid control and to constructive plans for their prevention. This will be particularly important during war conditions when large groups of injured men will be concentrated in hospitals.

Much has been contributed to an understanding of hemolytic streptococcal infection by the application of serological typing but many questions remain unanswered. Most of these pertain to the relationship of the type of infecting organism to the nature, severity, prognosis, and response to therapy of the clinical disease. It is to be hoped that a widespread adoption of this method will soon lead to a further understanding of these common and often serious infections.

\section{SUMMARY}

1. Hemolytic streptococci of the Lancefield Group A may be readily classified by the agglutination method of Griffith.

2. Modifications of this method are presented which increase its reliability.

3. Data obtained by the application of these methods to strains of hemolytic streptococci isolated from 260 individuals are presented. One hundred and forty-eight of these were suffering from active infections; 112 were healthy carriers.

4. These data indicate that:

$a$. Hemolytic streptococci of a small number of types are responsible for nearly all of the infections in any season in San Francisco. $b$. The same types do not predominate in every season.

c. The types predominating in respiratory infections are also those most commonly isolated from "surgical" infections and from the excised tonsils.

$d$. Type 25 was isolated more than twice as frequently from cases of otitis media than any other type and therefore appears to have been more invasive during this 2 -year period than other types.

$e$. Strains from middle ear infections were more readily typable than those from other sources.

5. These observations are compared with those obtained by other workers and their significance is discussed.

I am grateful to the Lederle Laboratories, who supplied generous amounts of type specific rabbit serum, and to Dr. F. W. Griffith, who also supplied serums for certain types.

\section{BIBLIOGRAPHY}

1. Lancefield, R. C., A serological differentiation of human and other groups of hemolytic streptococci. J. Exper. Med., 1933, 57, 571.

2. Hare, R., Sources of haemolytic streptococcal infection of wounds in war and civil life. Lancet, 1940, $1,109$.

3. Rantz, L. A., and Keefer, C. S., The distribution of hemolytic streptococci groups A, B and C in human infections. J. Infect. Dis., 1941, 68, 128.

4. Sherman, J. M., The streptococci. Bact. Reviews, 1937, $1,1$.

5. Griffith, F., The serological classification of streptococcus pyogenes. J. Hyg., 1935, 34, 542.

6. Ward, H. K., and Rudd, G. V., Studies on haemolytic streptococci from human sources; cultural characteristics of potentially virulent strains. Australian J. Exper. Biol. and M. Sc., 1938, 16, 181.

7. Neisser, H., Serological typing of streptococcus pyogenes and its application to certain infective conditions. J. Path. and Bact., 1939, 48, 55.

8. Griffith, F. W., and Allison, V. D., Annual Report of the Chief Medical Officer to the Ministry of Health, 1936.

9. Green, C. A., Serological types of hemolytic streptococci in an epidemic of scarlatina. J. Hyg., 1937, 37, 318.

10. de Waal, H. L., The serological types of haemolytic streptococci in relation to the epidemiology of scarlet fever and its complications. J. Hyg., 1940, 40, 172.

11. Colebrook, Dora C., The source of infection in puerperal fever due to hemolytic streptococci. Med. Res. Counc. Special Report Series, No. 205, London, His Majesty's Stationery Office, 1935. 
12. Shaw, C., Serological grouping and typing of haemolytic streptococci from various human sources. Lancet, 1937, 2, 1193.

13. Bailey, J. H., The types of hemolytic streptococci found in scarlet fever patients and in the throats of grammar school children. Am. J. Hyg., 1939, 29, 107.

14. Pauli, R. G., and Coburn, A. F., Studies on the serological typing of streptococcus hemolyticus. J. Exper. Med., 1937, 65, 595,

15. Keogh, E. V., Simmons, R. T., and Wilson, H., Streptococcus pyogenes (Group A). A review of 1,341 strains collected from various human sources. Australian J. Exper. Biol. and M. Sc., 1941, 19, 51.

16a. Kodama, T., Tiku, Y., Kodaira, T., and Kodama, A., The serological grouping and typing of the hemolytic streptococci isolated in Tokyo. I. Kitasato Arch. Exper. Med., 1937, 14, 245.

b. Kodama, T., Ozaki, M., Nisyama, S., and Tiku, Y., The serological grouping and typing of the hemolytic streptococci isolated in Tokyo. II. Ibid, 1938, $15,162$.

c. Kodama, T., Ozaki, M., Nisiyama, S., Igarasi, J., Tiku, Y., and Kawamura, H., The serological grouping and typing of the hemolytic streptococci isolated in Tokyo. III. Ibid, 1939, 16, 110.

17. Rantz, L. A., The hemolytic streptococci. Studies in the carrier state in the San Francisco area. J. Infect. Dis., 1941, 69, 248.

18. Miles, A. A., Schwabacher, H., Cunliffe, A. C., Ross, J. P., Spooner, E. T. C., Pilcher, R. S., and Wright, J., Hospital infection of war wounds. Brit. M. J., $1940,2,855$.
19. Kuttner, A. G., and Krumwiede, E., Observations on the effect of streptococcal upper respiratory infections on rheumatic children: A three year study. J. Clin. Invest., 1941, 20, 273.

20. Brown, W. A., and Allison, V. D., Carriers and return cases in scarlet fever. J. Hyg., 1935, 35, 283.

21. Loewenthal, H., Type-specific and group-specific sera against streptococci. Brit. J. Exper. Path., 1934, $15,298$.

22. Lyons, C., Immunotransfusion and antitoxin therapy in hemolytic streptococcus infections. J. A. M. A., 1935, 105, 1972.

23. Platou, E. S., Dwan, P. F., and Hoyt, R. E., Streptococcus convalescent serums (scarlatinal). The potentialities of type specific pools. J. A. M. A., 1941, 116, 11.

24. Coburn, A. F., and O'Connell, S., Advances in serological typing and of streptococcus haemolyticus. Proc. Soc. Exper. Biol. and Med., 1939, 40, 645.

25a. Lancefield, R. C., Type specific antigens of Matt and Glossy variants of Group A hemolytic streptococci. J. Exper. Med., 1940, 71, 521.

b. The significance of $M$ and $T$ antigens in the cross reactions between certain types of Group A hemolytic streptococci. Ibid, 1940, 71, 539.

26. Coburn, A. F., and Pauli, R. H., Interaction of host and bacterium in the development of communicability by streptococcus haemolyticus. J. Exper. Med., 1941, 75, 551.

27. Keefer, C. S., Rantz, L. A., Shuman, H. H., and Rammelkamp, C. H., The distribution of hemolytic streptococci in 819 cases of infection. Arch. Int. Med. (In press.)

28. Rantz, L. A., Unpublished observations. 